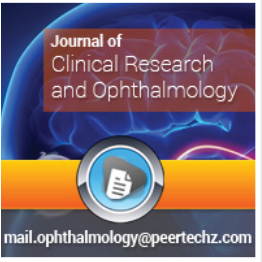

\title{
Journal of Clinical Research and Ophthalmology
}

Rani Ranabhatt ${ }^{1}$, Himanshi

Aggarwal $^{2}$, Saumyendra V Singh ${ }^{3 *}$ and Vinit Shah'

'Junior Resident, Department of Prosthodontics, Faculty of Dental Sciences, King George's Medical University UP, Lucknow, Uttar Pradesh, India. ${ }^{2}$ Senior resident, Department of Prosthodontics, Faculty of Dental Sciences, King George's Medical University UP, Lucknow, Uttar Pradesh, India. ${ }^{3}$ Professor Junior Grade, Department of Prosthodontics, Faculty of Dental Sciences, King George's Medical University UP, Lucknow, Uttar Pradesh, India.

Received: 12 March, 2018

Accepted: 17 March, 2018

Published: 19 March, 2018

*Corresponding author: Saumyendra V Singh, Professor Junior Grade, Department of Prosthodontics, Faculty of Dental Sciences, King George's Medical University UP, Lucknow, Uttar Pradesh, India;

E-mail: drhimanshi84@gmail.com

Keywords: Enucleation; Exposed intraocular hydroxyapatite implant; Ocular prosthesis; Retinoblastoma.

https://www.peertechz.com

\section{Case Report}

\section{Modified prosthetic rehabilitation of an enucleated pediatric patient with exposed intraocular implant}

\section{Abstract}

\begin{abstract}
Introduction: Retinoblastoma is one of the leading cancers in children below 5 years, leaving an ocular defect after enucleation. The loss of an eye requires early replacement so that socket contraction is minimal, growth of surrounding tissues is less retarted and the patient may return to a normal social life. Primary placement (at the time of enucleation) of hydroxyapatite intraocular implants is done in order to prevent volume deficit and increase motility of the prosthesis. Exposure of this implant is a common complication where the amount of exposure usually decides the treatment modality. Large exposures requires surgical correction whereas small exposures may be managed conservatively.
\end{abstract}

Patient: This article describes a pediatric patient with exposed hydroxyapatite intraocular implant managed successfully with a vaulted ocular prosthesis.

Discussion: Simple prosthetic modifications leading to relief over exposed primary hydroxyapatite implant site may improve the patient's quality of life without the risks of secondary surgery. Conservative treatment with topical steroid and antibiotics along with prosthetic manipulation in form of vaulted ocular prosthesis or delayed fitting of ocular prosthesis is recommended.

\section{Introduction}

Retinoblastoma is a highly malignant intraocular tumour that occurs commonly in children less than 5 years of age [1]. In advanced cases, management includes enucleation with radiotherapy and chemotherapy. However enucleation during infancy can lead to severely underdeveloped bony orbital growth, cosmetic deformity and facial asymmetry [2]. To prevent this complication, intraocular implants are usually placed at the time of surgery. These reduce volume deficit, improve prosthesis mobility and reduce potential for contracture, thereby helping in achieving better all round results $[3,4]$.

Intraocular implants placed at the time of enucleation are known as primary implants and those placed in a second surgery are known as secondary implants. These may be integrated (hydroxyapatite implants) or non-integrated (acrylic, glass and silicone) depending on the material. There was higher risk of implant exposure and extrusion with nonintegrated type of implants because of which the concept of integrated implants emerged $[5,6]$. Though, integrated hydroxyapatite intraocular implants may get exposed, there is minimal chance of extrusion. In case of a large implant exposure surgical removal may be required. Small exposures may be amenable to treatment by grafting the exposure site or modifying prosthetic procedures that is by vaulting the intaglio surface of the ocular prosthesis, as conventional rehabilitation can lead to frictional irritation at junction of implant and soft tissue, leading to pain and further exposure.

This article describes a pediatric patient with exposed primary hydroxyapatite intraocular implant, successfully rehabilitated using modified vaulted ocular prosthesis.

\section{Case report}

A 14 month old toddler male was referred to the department to replace his left eye (Figure 1). The patient underwent enucleation 3 months back to remove a retinoblastoma, with adjuvant vincristine, carboplatin and etoposide chemotherapy. On examination, the enucleated left eye had a primary hydroxyapatite implant (Figure 2). The implant was exposed with soft tissue margins inflamed as the patient's existing ocular prosthesis was probably constantly irritating the soft tissue implant junction. The superior and inferior fornices were normal with complete closure. A stock conformer was placed along with instructions to apply dexamethasone (Ocupol-D) ointment three to four times daily for a period of 6 weeks, to 
decrease the inflammation. Stock conformers are usually a thin shell of acrylic resin with concavity on the tissue surface of the conformer, which does not contact the exposed implant site.

After 6 weeks, a minimal pressure ocular impression with a customised ocular tray was made using a low viscosity condensation silicone \{Oranwash L, Zermach, Zhengzhou Shengxin Medical Instrument Co., Ltd., Zhengzhou, China ( Mainland) $\}$ and poured in dental stone type III\} using a two pour technique (Figure 3). On the cast, wax pattern was made using ocularist's wax (factor 2 Inc, Arizona) by conventional technique in which separating media was applied and wax layer was poured subsequently developing the contour of the eye. The contours of the wax patterns were verified by placing in the socket and comparing with the natural scleral contours from all aspects. Iris extracted from stock eye (matching to patient's normal was selected) was placed using graphgrid method [6], and verified by comparing with natural iris location in all gazes (Figure 4). An acrylic bead was placed over the iris to serve as an orientation groove, to prevent displacement of iris during the packing and curing stages. The wax pattern was invested, dewaxed and mold packed with heat cure polymerized tooth colored acrylic resin mixed with clear acrylic resin which improves the translucency of the ocular prosthesis. The ocular prosthesis was processed, finished and polished conventionally. Characterization of the prosthesis was carried out in accordance to the normal eye and then a layer of clear acrylic was applied over the characterized surface of the prosthesis in order to retain the characterization.

After polishing of the prosthesis, the area of the exposed intraocular implant was marked in the ocular prosthesis using pressure indicating paste (Figure 5). The marked area was vaulted out (Figure 6) and subsequent applications of pressure indicating paste were done until the tissue surface of the prosthesis made no contact over the exposed implant.

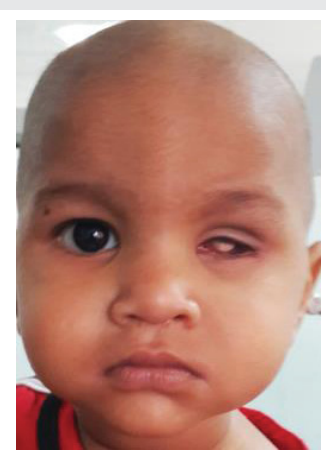

Figure 1: Preoperative photograph of the patient.

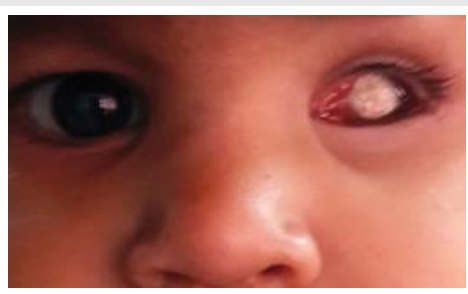

Figure 2: Enucleated socket with exposed primary hydroxyapatite implant.

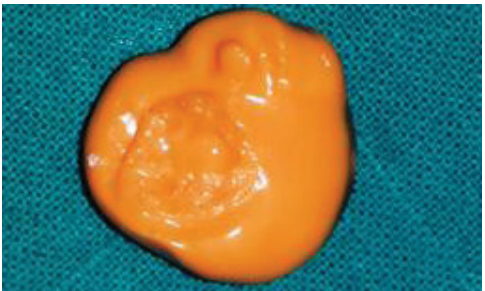

Figure 3: Ocular impression using low viscosity silicone.

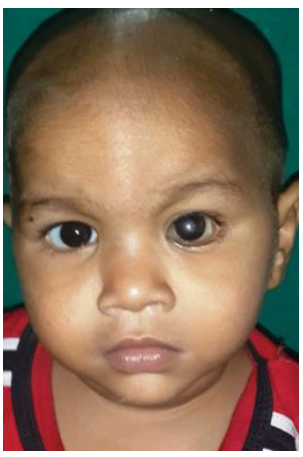

Figure 4: Wax pattern try-in procedure.

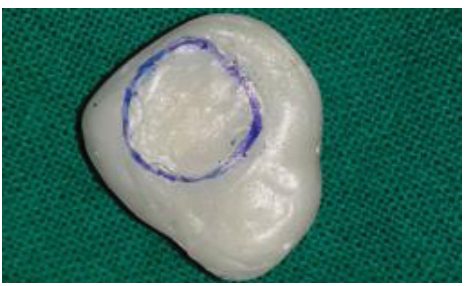

Figure 5: Area of implant exposure marked on the tissue surface of final prosthesis.

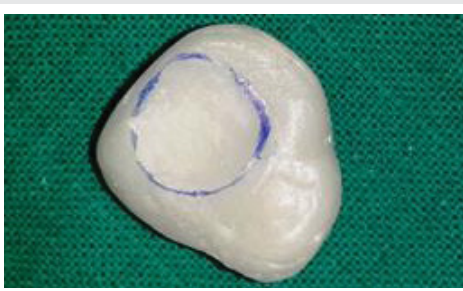

Figure 6: Vaulted ocular prosthesis.

The prosthesis after the final vaulting was finished, polished and delivered to the patient (Figure 7). In order to prevent subsequent marginal inflammation, the vaulted ocular prosthesis did not make any contact at the area of implant exposure and hence reducing uneventfully chances of further implant exposure. A stock conformer was placed along with instructions to apply dexamethasone (Ocupol-D) ointment three to four times daily for a period of 6 weeks, to decrease the inflammation. Stock conformers are usually a thin shell of acrylic resin with concavity on the tissue surface of the conformer, which does not contact the exposed implant site.

\section{Discussion}

The management of patients with exposed primary implants becomes complicated if surgical grafting needs to be done, as it exposes the patient to the risks of a second 


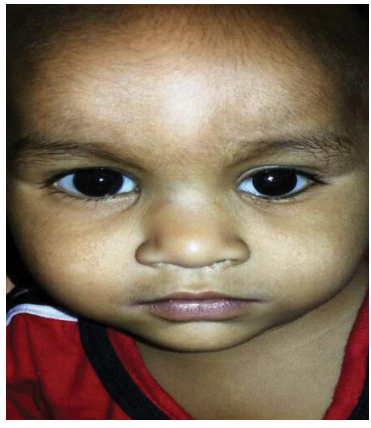

Figure 7: Post-operative photograph of the patient.

surgery with unpredictable success. More exposures of human bone hydroxyapatite $(8.16 \%)$ and bovine bone hydroxyapatite $(7.69 \%)$ have been reported than coralline hydroxyapatite implants (2.22\%) [7]. Oculoplastic surgeons use many kinds of patch grafts, such as amniotic membrane [8], sclera, dermis, hard palate mucosa and autogenous retro-auricular myoperiosteal grafts [9], to cover exposed hydroxyapatite implants, with inconsistent results.

Intraocular implant exposure can be early onset (before ocular prosthesis) or late onset (after ocular prosthesis). Factors predisposing to exposure of porous anophthalmic implants are orbital content of the patients and surgical techniques of implantation. Less ocular tissue may predispose to early exposure. Shallow implantation and evisceration without posterior sclerotomy may also predispose to exposure. Injudicious antibiotic use and smaller implants have been reported not to decrease the risk of implant extrusion [10]. Additional mechanisms proposed regarding the incidence of exposure are excessive tension on wound edges at primary closure, chronic mechanical irritation of the rough surface of the porous implant on native tissues, and an immune or chemically mediated inflammation [11]. In any kind of onset, conservative treatment with topical lubricants and prophylactic antibiotics can be enough in exposure smaller than $3 \mathrm{~mm}$ where spontaneous healing may occur, while implant exposure larger than $3 \mathrm{~mm}$ needs to be corrected with patch grafts underneath vascularized conjunctival flaps. In late onset exposures, artificial eye can be vaulted to reduce contact irritation [12].

Simple prosthetic modifications leading to relief over exposed primary hydroxyapatite implant site may improve the patient's quality of life without the risks of secondary surgery. Conservative treatment with topical steroid and antibiotics along with prosthetic manipulation in form of vaulted ocular prosthesis or delayed fitting of ocular prosthesis is recommended. If the patients respond to conservative treatment, topical treatment is tapered and functional vaulted prosthesis is maintained to improve the esthetic outcome. If exposures persist, surgical treatment using grafts serves as the last treatment resort in such cases. Cases non responsive to surgical management required replacement with new implant following removal of exposed implant [13].

\section{Conclusion}

Simple prosthetic modifications leading to relief over exposed primary hydroxyapatite implant site may improve the patient's quality of life without the risks of secondary surgery. Vaulted prosthesis can serve as a valuable treatment modality as in cautiously selected cases.

\section{References}

1. Eagle RC (1992) Retinoblastoma and simulating lesions. In: Duane TD editor. Duane's Clinical Ophthalmology, Foundations. 3: 429:483. Link: https://goo.gl/1t78vC

2. Peylan RN, Bin NA, Skleir LM, Bibas A, Koplewitz B, et al. (2001) Orbital growth retardation in retinoblastoma survivors: Work in progress. Med Pediatr Oncol 37: 465:470. Link: https://goo.gl/qUwuxF

3. Custer PL, Kennedy RH, Woog JJ, Kaltreider SA, Meyer DR (2003) Orbital Implants in Enucleation Surgery: a Report by the American Academy of Ophthalmology. Ophthalmology 110: 2054-2061. Link: https://goo.gl/zQZTFC

4. Nunnery WR, John DN, Hetzler KJ (2003) "Enucleation and Evisceration" In: Spaeth, George, ed. Ophthalmic Surgery: Principles and Practice 3rd ed. Philadelphia, PA: Elsevier 485-507.

5. Trichopoulos N, Augsburger JJ (2005) Enucleation with unwrapped porous and nonporous orbital implants: a 15-year experience. Ophthal Plast Reconstr Surg 21: 331-336. Link: https://goo.gl/oU8JUB

6. Guttal S, Patil NP, Vernekar N, Porwal A (2008) A Simple Method of Positioning the Iris Disk on a Custom-Made Ocular Prosthesis. J Prosthodont 17: 223227. Link: https://goo.gl/4VXh3z

7. Pongprayoon C (2008) Outcome of porous implants: Incidence of complications, management, and morbidity. J Med Assoc Thai 2008; 91: 8185. Link: https://goo.gl/ZZE3HK

8. Lee-Wing MW (2003) Amniotic membrane for repair of exposed hydroxyapatite orbital implant. Ophthal Plast Reconstr Surg 19: 401-402. Link: https://goo.gl/KKQhZW

9. Liao SL, Kao SC, Tseng JH, Lin LL (2005) Surgical coverage of exposed hydroxyapatite implant with retroauricular myoperiosteal graft. $\mathrm{Br} J$ Ophthalmol 89: 92-95. Link: https://goo.gl/nGKCb9

10. Liu D (2007) Evisceration techniques and implant extrusion rates: A retrospective review of two series and a survey of ASOPRS surgeons. Ophthal Plast Reconstr Surg 23: 16-21. Link: https://goo.gl/dwq3nL

11. Deacon BS Orbital Implants and Ocular Prostheses: A comprehensive review. Journal of Ophthalmic Medical Technology Link: https://goo.gl/wH49dk

12. Chu HY, Liao YL, Tsai YJ, Chu YC, Wu SY, (2013) Use of extraocular muscle flaps in the correction of orbital implant exposure. PLoS One. 25: 8(9):e72223. Link: https://goo.gl/QP2uSt

13. Aggarwal H, Kumar $P$, Eachempati $P$, Alvi HA (2015) Different Intraorbital Implant Situations and Ocular Prosthetic Rehabilitation. J Prosthodont Link: https://goo.gl/TuNFJN

Copyright: (c) 2018 Ranabhatt R, et al. This is an open-access article distributed under the terms of the Creative Commons Attribution License, which permits unrestricted use, distribution, and reproduction in any medium, provided the original author and source are credited. 